\title{
Immigration Status as the Foundational Determinant of Health for People Without Status in Canada: A Scoping Review
}

\author{
Monica Gagnon ${ }^{1}\left[\right.$ D $\cdot$ Nisha Kansal $^{2} \cdot$ Ritika Goel $^{3} \cdot$ Denise Gastaldo $^{4}$
}

Accepted: 10 September 2021 / Published online: 3 October 2021

(c) The Author(s), under exclusive licence to Springer Science+Business Media, LLC, part of Springer Nature 2021

\begin{abstract}
Migration is increasing at unprecedented rates worldwide, but inadequate mechanisms for granting citizenship or permanent residence have rendered many immigrants without legal status. We study the health of people without immigration status in Canada, building on a 2010 review on being without status and health. We employ an expanded definition of health, guided by the WHO Social Determinants of Health $(\mathrm{SDoH})$ framework. Using a scoping review methodology, we reviewed literature from 2008 to 2018 on the SDoH of people without legal immigration status in Canada, selecting 33 articles for analysis. We found that structural determinants of health, such as stigmatization and criminalization, and intermediary determinants, such as fear of deportation and healthcare avoidance, produce ill health. We show how different social positions are produced by $\mathrm{SDoH}$, finding immigration status to be the foundational determinant of health for people without status in Canada. We argue that lack of immigration status as a SDoH is missing from the WHO framework.
\end{abstract}

Keywords Immigration $\cdot$ Canada $\cdot$ Undocumented $\cdot$ Illegal $\cdot$ Social determinants of health $\cdot$ Access to health care

\section{Introduction}

Irregular migration, or the movement of people outside of regular migration channels [1], is the fastest growing form of international migration across the globe. In high-income countries, this type of migration is associated with neoliberal market demands for a readily available, cheap and flexible workforce [2]. In the case of Canada, people without legal immigration status usually enter the country with some form of status such as a temporary work permit, student visa, or tourist visa, which later expires, or a refugee claim which fails or is withdrawn, leaving the person without status [3]. The Canadian immigration system is complex to navigate, with people frequently shifting in and out of status,

Monica Gagnon

monica.gagnon@mail.utoronto.ca

1 Dalla Lana School of Public Health, University of Toronto, Toronto, ON, Canada

2 Faculty of Health Sciences, McMaster University, Hamilton, ON, Canada

3 St. Michael's Hospital, Academic Family Health Team, Toronto, ON, Canada

4 Lawrence S. Bloomberg Faculty of Nursing, University of Toronto, Toronto, ON, Canada often dependent on third parties like employers or partners to secure legal immigration status [4]. They have limited options for obtaining permanent immigration status, and live under the threats of arrest, detention, and deportation [5]. People without status are denied most health, social, and legal services [5], with direct and wide-ranging implications for their health and wellbeing. Because of this varied and shifting state of belonging, not having citizenship or permanent residency in Canada has been referred to as having "precarious" legal status, defined by the conditionality of one's presence and access to services [3]. In this paper, we focus in particular on the population of people with precarious status who have no legal immigration status in Canada, using the terms "without status," or "non-status."

This paper builds on Magalhães, Carrasco, and Gastaldo's 2010 review [5], which focused on how being without status in Canada affects people's health, service access, and working conditions, covering the 1999-2008 period. We reviewed the literature published over the following ten years, expanding on the previous review in order to include other social determinants of health (SDoH) affecting people without status in Canada. We use a broad definition of health that incorporates social, spiritual, emotional, and physical health and wellbeing. Our study is unique in bringing together the health and social sciences literatures to provide a more 
comprehensive understanding of the health and social position of immigrants without status in Canada. We provide an update on the state of the literature and present a new representation for conceptualizing immigration status as the foundational determinant of health for immigrants without status in Canada.

\section{Conceptual Framework}

Migration has traditionally been conceptualized in the health sciences either as an individual or family undertaking with the goal of economic improvement, or as an epidemiological issue, where morbidity and mortality reveal trends in human movement within and across national borders $[6,7]$. However, these views neglect to consider that at the core of irregular international migratory processes are millions of people searching for decent living and working conditions. In this paper, we bring a postcolonial perspective to the study of migration and health. We believe that studies about immigration must take into account the principles of destruction and violence that operate in modern democracies, where imperialist, neoliberal capitalist competition among nation-states, aiming at wealth concentration, simultaneously promotes irregular migration and leads to criminalization of unauthorized immigrants [2]. Nevertheless, irregular migration continues, and many immigrants are not entitled to rights in the nations where they reside [8]. Our analysis of the SDoH affecting people without status takes into account the ways in which the lives of people without legal immigration status are shaped by discourses of "illegal human existence" accompanied by exploitative relations and unjust suffering [7, 9].

The World Health Organization (WHO)'s SDoH framework examines how structural and intermediary SDoH shape people's living circumstances, resulting in particular social positions that can promote or impede their health [10]. Structural determinants encompass political and socioeconomic contexts, which include social policies and social positions (e.g. race/ethnicity and income level). Intermediary determinants include specific material circumstances (e.g. food availability, working conditions), biological, behavioural and psychosocial factors (e.g. fear of deportation, capacity for social mobilization) [10]. These structural and intermediary determinants create the conditions for differential health consequences. For example, in Canada, where neocolonial and neoliberal political-economic logics for social stratification are dominant, racialized individuals and immigrant groups have limited access to social and material resources and bear a greater burden of health damaging conditions as a result $[2,7]$. Poverty and material deprivation alone do not produce low social positions; at the core of the production of inequity is social injustice [11]. The result is a social hierarchy that varies along a gradient from extreme privilege to profound disadvantage, and immigrants without status are at the bottom of this hierarchy [7].

With a postcolonial perspective, we believe the $\mathrm{SDoH}$ can help health scholars think about how political and socioeconomic practices lead to physical, mental, and social health consequences for individuals and groups, particularly those without status. While migration has been noted as a social and public health issue, seldom has a SDoH approach been used to understand the inequities produced in the migratory process [6]. In summary, we use the WHO SDoH framework as a tool to study the mechanisms of health inequity, exposing the importance of structural and social circumstances for health. Thinking about immigration through the lens of structural and intermediary SDoH offers an opportunity to better understand the health consequences that manifest in unnecessary suffering, disease, and reduced life expectancy among immigrants without status in Canada, and to denounce, mitigate, or transform oppressive social discourses and practices.

\section{Methodology}

\section{Search Strategy}

We utilized the scoping review method of literature review [12]. In order to understand the landscape of recent literature and not duplicate work done by Magalhães et al. [5], we limited our search to articles published between 2008 and 2018. Searches were conducted in Medline, PsycInfo, CINAHL, Web of Science, and Sociological Abstracts in order to establish a broad view of the issue from both the social and health sciences literatures. In addition to searching peerreviewed databases, we searched Google Scholar for studies citing Magalhães et al. [5]. Our exclusion criteria were: articles not focusing on the Canadian context, articles published in a language other than English or French, literature reviews, books, book reviews, theses, and gray literature. We also excluded articles that primarily discussed populations with forms of precarious immigration status other than being without status, such as refugee claimants and temporary foreign workers. The search resulted in 9419 titles which were reviewed by one author (NK) who selected 475 for abstract review. Two authors (MG, NK) conducted the abstract review, selecting 55 articles for full-text screening. These articles were divided among all authors, with two authors reviewing the full text of each article to determine the final dataset. Thirty-three articles were ultimately included in our analysis based on the above inclusion and exclusion criteria. See Table 1 for profiles of selected articles. 


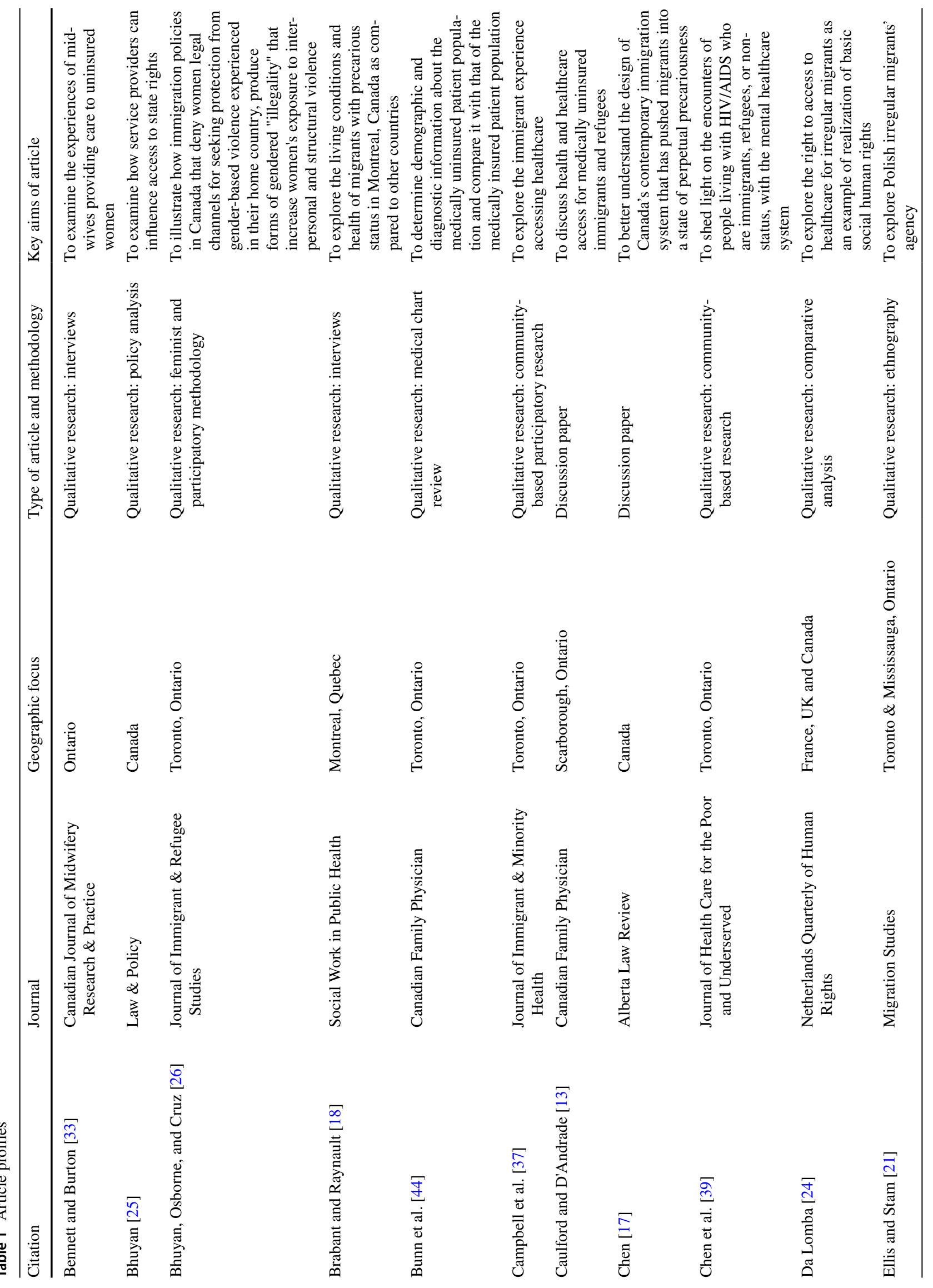




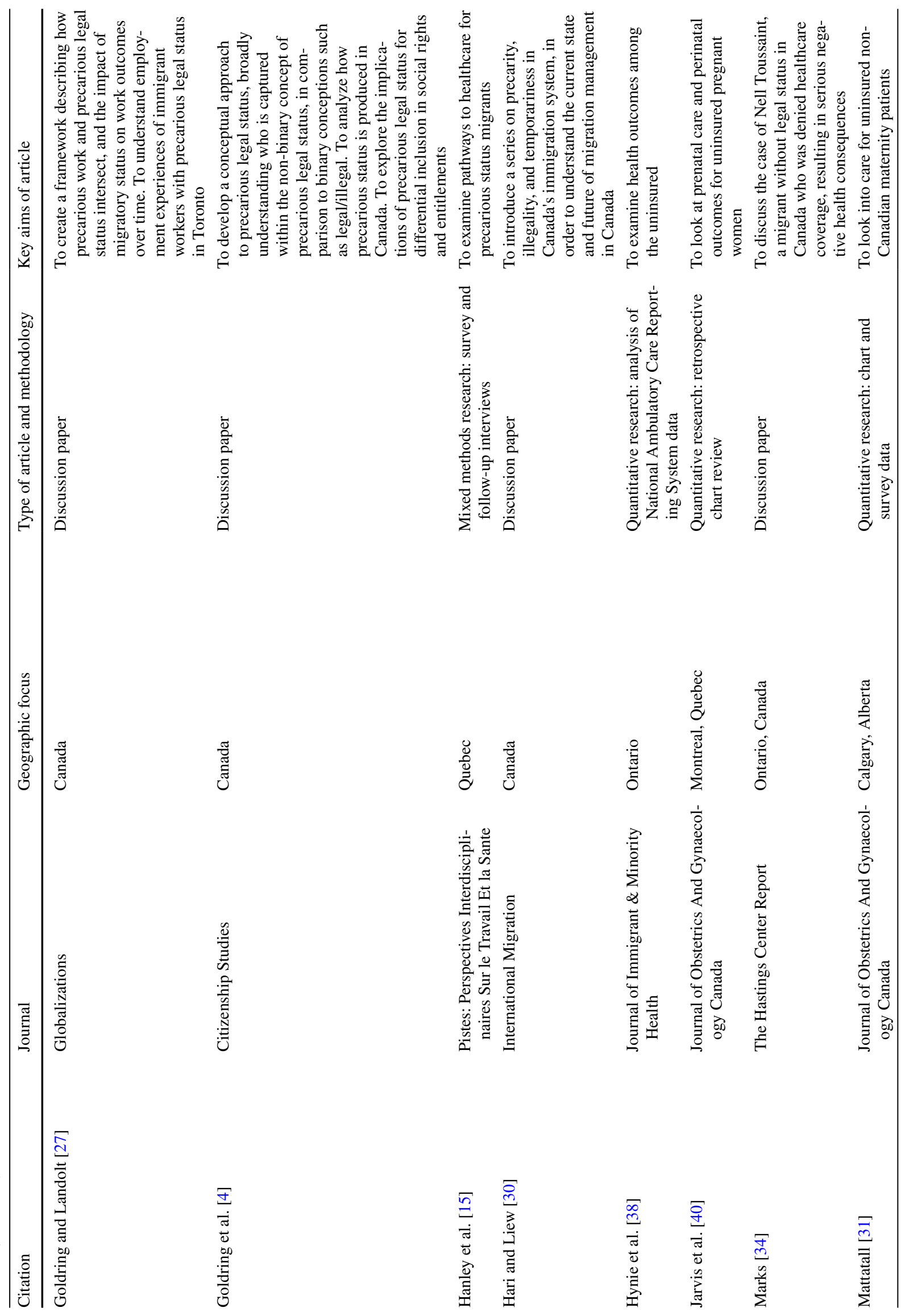




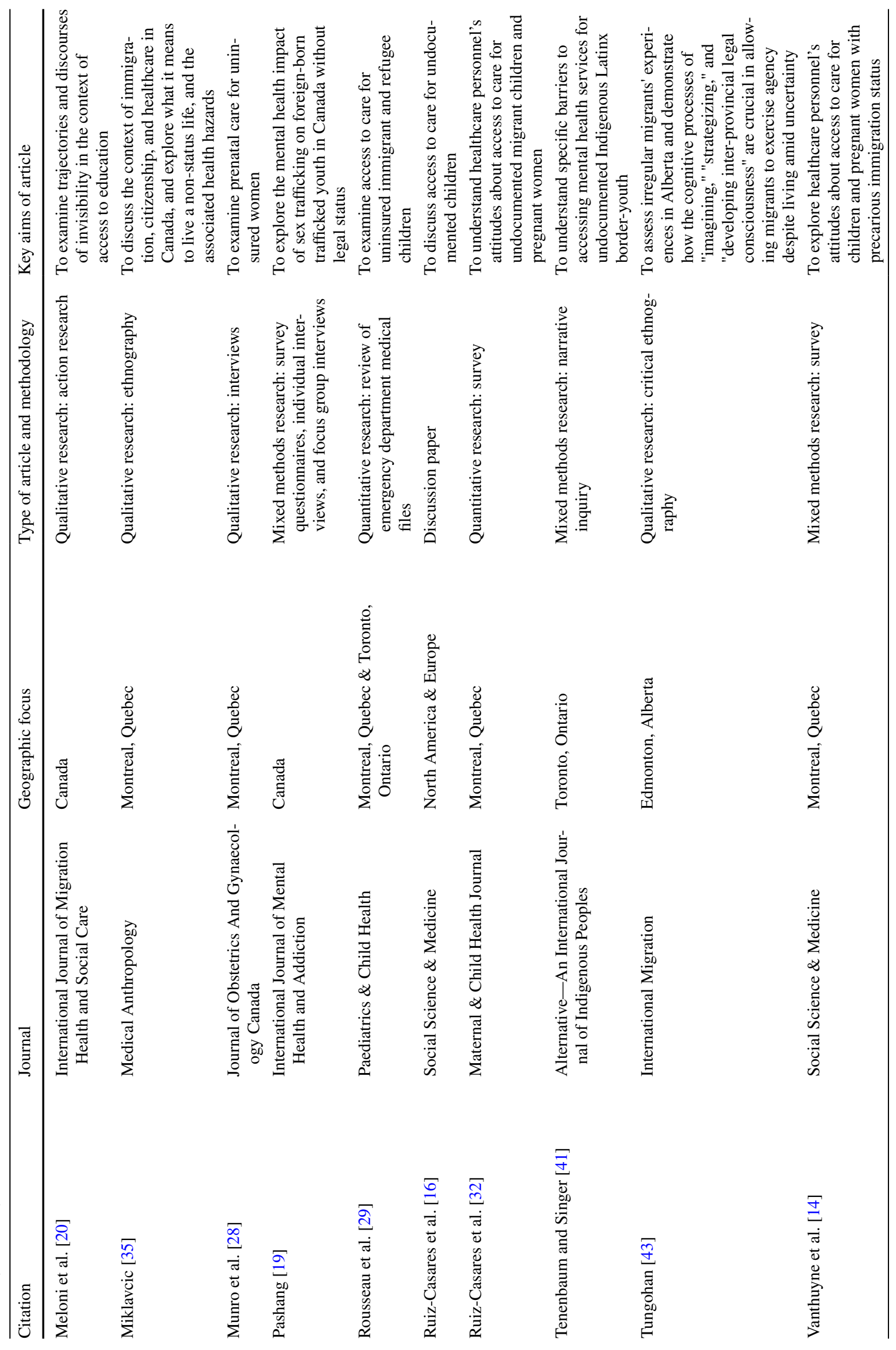




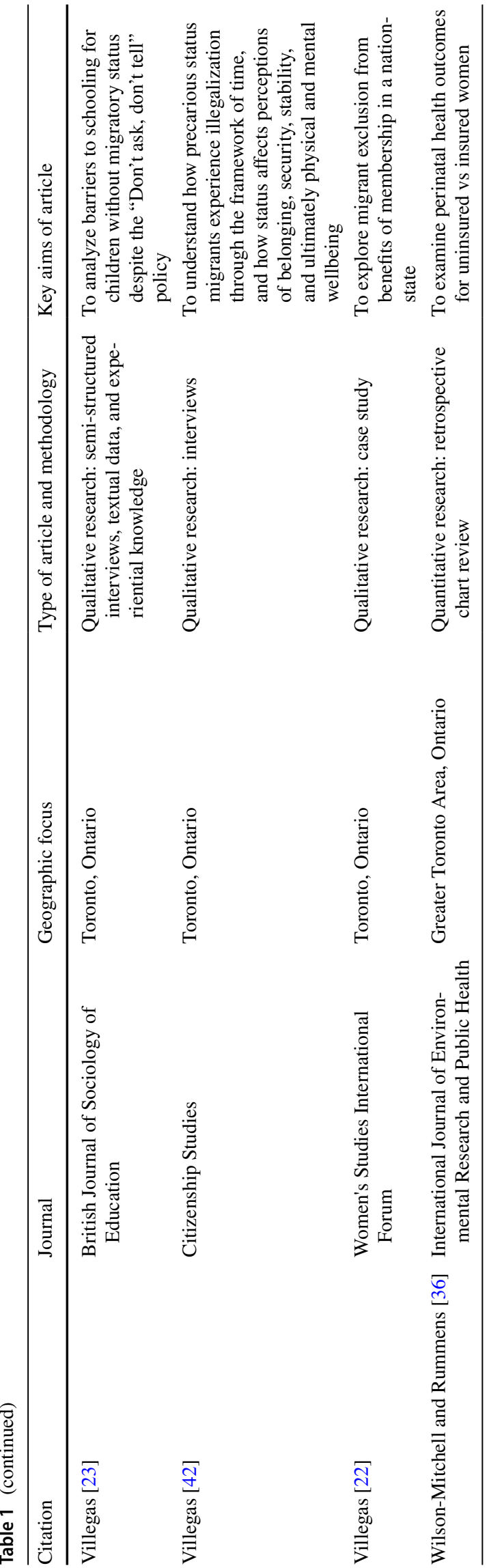

\section{Analytical Strategy}

Analysis was conducted in two phases, with the participation of all authors in the inductive phase and three authors (MG, NK, DG) in the deductive phase. In the inductive phase, we identified the theoretical frameworks that guided the studies and grouped articles as either social sciences or health sciences to compare their contributions, using the journals and the authors' academic degrees and institutions to establish their disciplines. We also identified research, practice and policy recommendations made by the articles' authors. In our inductive analysis, we identified multiple themes and subthemes reflecting the articles' main findings about the health and wellbeing of immigrants without status in Canada. Next, we conducted a deductive analysis, using the WHO SDoH framework as a guide. We organized the themes from the inductive analysis under the three main WHO SDoH categories: structural determinants of health, intermediary determinants of health, and impact on equity in health and wellbeing, or health consequences. Once the inductive and deductive analyses were complete, we revisited our original themes to ensure the final analysis remained grounded in the articles' content. This process led to the inclusion of a few additional themes. The final list of analytical themes and subthemes is presented in Table 2.

\section{Results}

\section{Profile of the Literature}

In the decade since Magalhães et al. [5] published their paper, there has been a small but steady stream of research about the health implications of living without immigration status in Canada. Articles have been published in a wide range of journals including health and medical journals, immigration and citizenship journals, sociology, anthropology and legal journals (see Table 1 for article profiles). While some articles discuss Canadian trends broadly, or Canada in relation to other countries, most focus on particular metropolitan regions in Canada. The majority of studies are either from Toronto or Montreal, perhaps due to those cities having large immigrant populations. Methodologically, there is a dominance of qualitative studies.

While the fields of health and social sciences are both influenced by principles of human rights and equity, we identified distinct differences between the ways in which authors in the health and social sciences conceptualize the impact of being without status on health. Authors in the health sciences either implicitly or explicitly use frameworks pertaining to the $\mathrm{SDoH}$, health as a human right [13-17] or health equity [18], while social scientists approach the issue through conceptual frameworks such as deportability 
Table 2 Analytical themes and sub-themes

\begin{tabular}{|c|c|c|}
\hline Structural determinants of health & Intermediary determinants of health & Health consequences \\
\hline $\begin{array}{l}\text { Political views and practices in Canada } \\
\text { Institutionalization of temporariness } \\
\text { - Complexity of migratory system } \\
\text { - Politically produced precarious immigration } \\
\text { status } \\
\text { Stigmatization/illegalization/criminalization } \\
\text { - Considered morally inferior } \\
\text { - Considered taking advantage of the system/costly } \\
\text { - Threat to national security } \\
\text { (Un)deservingness } \\
\text { Invisibilization } \\
\text { - Limited data } \\
\text { - Unofficial healthcare provision } \\
\text { - "Don't ask, don't tell" policy } \\
\text { Rights } \\
\text { - Health as human right } \\
\text { - Health as a human right vs. right of citizens } \\
\text { Myth of universal healthcare } \\
\text { - Universal versus selective healthcare system } \\
\text { Intersectional social position } \\
\text { - Nationality/immigration status } \\
\text { - Social class/occupation } \\
\text { - Gender/sexuality } \\
\text { - 'Race'/ethnicity }\end{array}$ & $\begin{array}{l}\text { Living conditions } \\
\text { - Poor housing conditions } \\
\text { - Food insecurity } \\
\text { Working conditions } \\
\text { - Financial insecurity/low wages } \\
\text { - Precarious working conditions } \\
\text { - Deportability } \\
\text { Social practices } \\
\text { - Social isolation } \\
\text { - Social network mobilization } \\
\text { - Health care avoidance } \\
\text { Psychosocial conditions } \\
\text { - Lack of social support } \\
\text { - (In)visibility } \\
\text { - Fear of deportation } \\
\text { - Fear of debt } \\
\text { - Powerlessness/hopelessness } \\
\text { - Autonomy and resilience } \\
\text { Healthcare } \\
\text { - Lack of coverage } \\
\text { - Access does not ensure utilization } \\
\text { - Barriers and facilitators: gatekeeping/administra- } \\
\text { tive, sustainability, provider ideology } \\
\text { - Limited access to healthcare } \\
\text { - Fear of using services (deportation risk) } \\
\text { - Differential utilization according to social posi- } \\
\text { tion/intersectionality } \\
\text { - Debt due to healthcare } \\
\text { Social services } \\
\text { - Lack of access to education } \\
\text { - Barriers and facilitators: gatekeeping/administra- } \\
\text { tive, sustainability, provider ideology } \\
\text { - Limited access to social services } \\
\text { - Fear of using services (deportation risk) } \\
\text { - Differential utilization according to social posi- } \\
\text { tion/intersectionality }\end{array}$ & $\begin{array}{l}\text { Broad impact on health and wellbeing } \\
\text { Physical health } \\
\text { - Increased risk of complications } \\
\text { - Poorer health outcomes } \\
\text { - Accidents } \\
\text { - Domestic violence } \\
\text { - Pregnancy and obstetric issues } \\
\text { - Increased rate of HIV } \\
\text { Mental health and wellbeing } \\
\text { - Inability to plan for future } \\
\text { - Stress/Fatigue } \\
\text { - Anxiety } \\
\text { - Depression } \\
\text { - PTSD } \\
\text { - Addictions } \\
\text { Lower quality care } \\
\text { - Limited or lack of continuity of care } \\
\text { - Seeking care only for emergencies }\end{array}$ \\
\hline
\end{tabular}

[19], invisibility [20], illegalization or institutionalized precarious status [4, 21, 22], bordering [23], human rights [24] or theories of citizenship $[25,26]$. Social scientists tend to interrogate how social processes like illegalization and invisibilization hinder social justice for groups without status, but they seldom relate these processes to health consequences. Conversely, health scientists tend to emphasize access to healthcare, overlooking broader political and social influences and material circumstances that impact health.

\section{Structural Determinants of Health}

According to the WHO framework [10], structural determinants refer to the "interplay between the socioeconomicpolitical context, structural mechanisms generating social stratification and the resulting socioeconomic position of individuals" (p. 28). Our review reveals that the socioeconomic and political contexts are characterized by discourses and practices that support or thwart the ability of people without status to participate in social life in Canada, live with dignity, and achieve optimal health and wellbeing. Below, we present those themes described in the literature that relate to dominant ideas about nation-state, status temporariness, stigmatization, invisibilization, and the right to health and healthcare.

\section{Temporariness and its Institutionalization}

There are almost no pathways to citizenship or legal residency for people who are in Canada without status, marriage and humanitarian cases being exceptions. According to the articles reviewed, legal status is a politically produced and complex phenomenon [14, 21, 24, 27-29]. Canada's fragmented immigration system produces illegality, with temporary residency much easier to obtain than permanent status [4]. Chen [17] argues that growing numbers of immigrants are granted only temporary legal status in order to ensure a flexible labor force while minimizing government 
expenditure on benefits like healthcare. Goldring and Landolt [27] argue that limited opportunities for obtaining legal status are part of a "global citizenship and migration management regime," (p. 338) that furthers illegalization and exclusion in order to produce a cheap, exploitable workforce. Despite limited opportunities to secure permanent immigration status, the dominant view in Canada is that the responsibility to obtain status lies with the individual [17]. However, many of the authors of the articles in our review disagree. Hari and Liew [30] call for the implementation of clear pathways to residency in Canada, and according to Goldring, Berinstein, and Bernhard [4], the discourse needs to shift from an onus on individual responsibility to a demand for changes in immigration policy that would foster permanence rather than temporariness.

\section{Stigmatization of People Living Without Status: Illegalization and Criminalization}

The literature establishes that people without immigration status in Canada are popularly portrayed as morally inferior $[14,16,17]$, as taking advantage of Canada's generosity [24, $28,31]$, or as threats to national security $[24,30]$. According to the articles we reviewed, the idea that people without status do not deserve access to healthcare and social services because they do not contribute to the system is prevalent in Canada [16, 32]. For example, a problematic view noted by Vanthuyne et al. [14] is that only taxpayers and Canadian citizens are deserving of care, while those without status are undeserving because they do not contribute to the tax base, thereby straining the system for Canadians. The argument that people without status do not contribute has been challenged as incorrect, as these individuals do pay sales tax, effectively supporting a system from which they do not derive any benefit [13]. Still, our review highlights that irregular migration has come to be associated with criminality [21, 24, 33], and that people without status, particularly those who are racialized, are popularly perceived in Canada as abusive of Canadian institutions, having not arrived through "regular" channels [14, 16, 32]. Problematically, such views are prevalent among healthcare professionals $[14,16]$. This stigmatization and criminalization can lead to migrant illegalization, or what Villegas [22] calls a "process of excluding immigrants from the benefits associated with being members of a nation-state" (p. 192). The illegalization of people without status in Canada serves as justification for governments not fulfilling their right to health $[17,34]$. Provincial governments justify denial of most subsidized health services to non-status immigrants as a necessary result of limited resource allocation [17]. Some authors of the reviewed articles argue that such restrictions are rooted in racism and xenophobia $[30,33]$.

\section{Invisibilization of People Living Without Status}

According to our review, the lack of visibility of people without status in mainstream Canadian society compounds their marginalization [4]. Miklavic [35] describes invisibility as "ascribed to the illegal immigrant by the host country via exclusionary practices resembling social death" (p. 501). As a clear sign of their invisibility in research and policy, there are limited data on the numbers of people without status in Canada [16, 30, 31, 36], as well as limited data on their specific healthcare needs and usage [24]. Villegas [22] calls for more options for people without status to be able to safely document their presence in Canada in order to improve wellbeing and community participation. We discuss the particular issue of invisibility in the context of health and social services below.

\section{Health as a Human Right}

In some of the articles reviewed, the discourse of health as a human right is drawn on to support the promotion of health for all people in Canada. The right to health has been used as a justification for supporting expanded access to care for people without status [17, 34]. Some authors assert that withholding healthcare in Canada is a violation of human rights [17, 27]. Others call on Canada to uphold its commitment to the International Covenant on Economic, Social, and Cultural Rights, which recognizes the international right to health [16, 24, 34]. Ruiz-Casares et al. [16] describe the tension in Canada between the view that healthcare is a human right and the view that it is a right reserved for people with legal immigration status (citizens, permanent residents, or refugees with documents). Despite the presence of these human rights discourses, citizenship remains the dominant rationale for entitlement to healthcare and other services in Canada [27].

\section{The Myth of Universal Healthcare}

Authors of the reviewed articles acknowledge a prevailing view among Canadians that the healthcare system is universal, while noting that in practice, care is provided selectively $[14,16,29,35]$. This results in a tiered system, where care for those without public health coverage, including people without status, can be prohibitively expensive [37]. Even if individual physicians provide services for no compensation [35], most hospitals charge high fees for non-insured clients, who may not be able to pay, and therefore go without needed care [38]. While certain institutions like volunteer clinics serve people without status, they do not provide a sustainable or comprehensive solution [13]. Despite the indisputable fact that not everyone in Canada has access to healthcare, the dominant discourse maintains that healthcare is universal. 


\section{Social Position}

As noted above, the structural determinants of health illuminate the ways in which socioeconomic and political contexts create and interact with individuals' social and economic positions [10]. In the literature we reviewed, immigration status is one of many social positions that result in social and political exclusion in Canada, along with others such as race, class, and gender. Not having legal immigration status is a core element of low social position in Canada [21, 22, $24,37]$. Authors of the reviewed articles note that such low social positions are characterized by socioeconomic precarity [4, 29], vulnerability to abuse and precarious working conditions [28, 33], and experiences of stigmatization [39].

\section{Intermediary Determinants of Health}

According to the WHO framework, intermediary determinants of health are the everyday practices and processes that affect health, influenced by the operationalization of the structural determinants described above [10]. We identified three main themes in the literature, as well as subthemes, that we categorized under intermediary determinants of health: social practices and psychosocial conditions, living and working conditions, and healthcare and social services (see Table 2).

\section{Social Practices and Psychosocial Conditions}

While the WHO framework separates social or behavioral practices from psychosocial conditions or circumstances, we found the two to be intertwined in the literature, as people's psychosocial conditions are often revealed through their social practices. We present our findings, organized by subtheme, here.

Fear of Deportation and Social Isolation Fear of deportation among people without status is cited in the reviewed literature as a major impediment to accessing healthcare and social services $[15,16,20-22,25,37,39-41]$. There is a prevalent fear of government authorities in the non-status population [18] and an awareness of the perpetual threat of deportation [26, 42]. Service delivery organizations often ask for identification in order to establish entitlement, leading to avoidance of these organizations [4, 19]. Fear that healthcare information will be shared with immigration authorities can discourage utilization [15, 20, 21, 35]. Even if they are not afraid of being deported outright, people who have immigration or refugee applications in process may worry that service utilization could jeopardize application outcomes [17]. One strategy employed by people without status to avoid deportation is social isolation [18, 39, 41]. They make themselves invisible [22, 35], decreasing com- munity participation [42]. While isolation in these cases is a strategic practice, it can also be a result of a lack of social support and not knowing where to go for help [22, 41]. Studies show a lack of family psychological support [18] and limited feelings of belonging [22].

Healthcare Avoidance A highly cited behaviour among immigrants without status in Canada is healthcare avoidance $[18,24,35,40]$. As noted above, such avoidance is cited in connection with fear of deportation [15, 20, 21, 35], but cost is another significant reason for healthcare avoidance $[15,21,28,38]$, given that hospitals charge people without status for services. In addition, in order to seek care, many people have to give up work hours, increasing the total cost of care [22]. People may delay seeking care until conditions worsen $[9,19,26]$, presenting to the emergency department for critical conditions [25, 31]. Care may also be avoided because services do not meet specific needs [39]. Mental health services in particular lack culturally-informed and language-appropriate options, leading to underuse [41].

Multiple Responses: From Creative Strategizing to Powerlessness According to the literature, people without status may fall along an emotional spectrum that ranges from resilience to defeatism [26, 43]. The purposeful isolation described above is just one of many examples of what Ellis and Stam [21] call "creative strategizing" (p. 11) among people without status [15, 35, 42]. They may find other ways to act within oppressive power structures to improve their situations [43], such as mobilizing resources and networks in order to fulfill their present and future needs [15, 20, 42]. Some people without status feel that working in Canada fulfills a long-held ambition and feel a sense of increased autonomy and decision-making power, seeing challenges as opportunities [43]. Many engage with their communities in Canada and consider themselves deserving of entitlements and services [26]. However, people also report feeling powerless, helpless, hopeless, stuck, or unable to plan for the future $[18,19,21]$. They may experience a loss of motivation associated with waiting to acquire status [18] or knowing that they have no possibility for obtaining permanent status. They may feel suspended in a state of limbo knowing that they could be deported at any time [42]

\section{Living and Working Conditions}

The WHO framework identifies living and working conditions as material circumstances that are intermediary determinants of health [10]. The reviewed literature discusses differential access to decent living and working conditions as being tied to health and wellbeing for non-status immigrants in Canada. Many have poor living conditions [18, 26], experience food insecurity [26], and have limited work 
opportunities [35]. They may earn low wages [15, 35] and have poor working conditions [15, 18, 24, 42, 43]. Without legal status, they are often only able to access precarious work [21] which keeps them vulnerable to deportation, and they may be forced to accept low pay and poor conditions due to fear of their lack of status being exposed [18]. They may experience wage theft, gendered wage disparities, higher risk of injury [22], and sexual exploitation [19]. Furthermore, it can be difficult to shift out of a precarious work pathway, even if secure legal immigration status is eventually obtained $[18,43]$. Thus, there is a strong relationship between precarious immigration status and long-term unemployment [27].

\section{Healthcare and Social Services}

In the WHO framework, the healthcare system is characterized as an intermediary determinant of health [10]. Here we describe health system-related determinants discussed in the literature: lack of coverage, limited access, and other barriers and facilitators to utilization. While these themes overlap with the section on social practices and psychosocial conditions, we have kept them separate in our analysis because we view the themes here as specifically system-related determinants rather than social or psychosocial determinants.

Lack of Coverage Lack of health insurance coverage among people without status in Canada is highly cited in the literature $[4,15-18,24,28,29,33,36,40,44]$. This is because access to Canadian provincial and federal health insurance is directly linked to immigration status [38]. Therefore, as noted above, many people without status have to pay for care $[22,39]$. Though uninsured people do have the option of purchasing private health insurance, this is usually not feasible due to pre-existing conditions, high costs, and agerelated exclusions [13].

Limited Access to Health and Social Services Lack of coverage is directly associated with limited access to healthcare $[18,21,22,24,29,33,38]$. People without status in Canada are less likely than those with permanent status to be able to access emergency care, primary care, medications [37], and prenatal care $[15,28,36,40]$. They also have limited access to education $[20,21,23]$ and to official accreditation if they do complete schooling [18]. People without status have limited or no access to workers' compensation, employment insurance, or welfare [18]. They are also prevented from accessing settlement services and social assistance, and from participation in federally-funded language instruction classes [4].

Barriers and Facilitators to Utilization Even when people without status do have access to healthcare or social ser- vices, the literature indicates that access does not ensure utilization [16]. Barriers to utilization can be financial, logistical, or cultural [28]. As we have noted, cost is a major barrier to accessing healthcare, due to having to pay if one is without status $[15,28,40]$. As a result, people may experience debt resulting from healthcare costs $[15,18,22,28$, $33,40]$. Although people without status can access some healthcare through community clinics, such clinics may have inadequate capacity that limits access $[4,13]$. People may lack familiarity with the healthcare system, be unaware of available services, or be unable to find providers who will care for them in a culturally or linguistically appropriate manner [17, 39-41]. Those who are technically eligible for certain services may not know their rights [24].

Provider ideology can be either a barrier or a facilitator to accessing services. Some authors argue that healthcare providers in Canada have a moral obligation to protect those without status [14, 18]. However, Ruiz-Casares et al. [32] point out that even healthcare providers and staff who value human rights do not necessarily support expanding access to care for people without status. While some frontline workers may be able to exercise discretion as to who they agree to serve [4], in many cases, access to care depends on staff and providers' willingness to bend the rules [24]. Some providers feel ethically obligated to offer uninsured patients emergency care, but not non-emergency care [31]. Munro et al. [28] note that procedures for caring for those without status often have to be "arranged outside the regular pathway of care" (p. 602). By avoiding recording what services are provided and to whom, providers may be able to offer services [32]. However, lack of systematic documentation obfuscates the need for these services [25]. Caring for people without status in most healthcare settings is taken on as additional, unpaid work [4, 28, 33], and people may be turned away.

\section{Health Consequences}

While it is clear in the literature that structural and intermediary determinants impact the health and wellbeing of people without status in Canada, available evidence on specific health consequences is limited. Those articles that do cite specifics usually reference a particular group of people (e.g. pregnant women). Here we present the health consequences documented in the current literature in order to show what is known about the specific impact on health and wellbeing for people without status in Canada, as well as to reveal the outstanding knowledge gaps.

\section{Broad Impact on Health and Wellbeing}

Many of the articles we reviewed reference a general negative impact on the health and wellbeing of people without status in Canada without discussing specific health 
outcomes. Authors identify poor health outcomes for pregnant women [40] and poor outcomes in general due to careseeking delays [24]. Villegas [42] reports that not being able to plan for the future can have a negative impact on both physical and mental wellbeing.

\section{Physical Health Consequences}

Some articles identify specific physical health consequences of being without status, though the outcomes are most often for the entire uninsured patient population, as data to allow stratification based on type of immigration status are not usually available $[38,44]$. Uninsured people have higher rates of emergency department presentation for injuries and obstetrics issues than the general population [38]. Uninsured children have higher rates of emergency department presentation with musculoskeletal injuries and lacerations, and report higher rates of family violence than insured refugee claimant children [29]. There are higher rates of HIV-positive patients in the uninsured population [44]. People without status report higher rates of accidents, pregnancy, and childbirth compared to other groups of migrant workers [15].

\section{Mental Health Consequences}

Decreased mental wellbeing is cited in the literature as a consequence of being without status [18, 41]. Specific mental health consequences include stress, weakness and fatigue [21], depression, anxiety [15], suicidal thoughts, post-traumatic stress disorder, and substance abuse [29]. Uninsured people have higher rates of emergency department presentation for mental and behavioral health issues [38]. Chen et al. [39] report that some people have frequent anxiety attacks due to worries about HIV, legal status, underemployment, and financial insecurity.

\section{Lower Quality Care}

Many studies cite lower quality care for people without status than for the general population in Canada [16, 22, 33, 36, 38]. There is limited continuity of care for this population [37], which is especially problematic for those with chronic diseases [16]. There are fewer referrals, lack of tests, lack of follow up, and delays in consultation [18, 28]. Studies report inadequate prenatal care due to delays and missed screening opportunities [26, 36, 40].

\section{Recommendations for Research, Policy and Practice}

The authors of the reviewed articles recommend actions that could advance the achievement of health equity for people without status in Canada (see Table 3). More research is recommended on the complexity of migrants' experiences
[21], the health situations and consequences for people without status $[18,36,40]$, and the impact of lack of access to services and lack of opportunities to obtain permanent status for people with precarious status [14, 27, 29]. Authors also recommend research into how different forms of marginalization are compounded to produce exploitation [22]. Collaborative research is recommended beyond academia [20]. Policy recommendations include providing pathways for acquiring permanent legal status [17, 19, 42]; upholding the right to health and other human rights protections in Canada's health, work and immigration policies [24, 27, $34]$, addressing disparities in access to care [33, 36], and ensuring providers are compensated to provide care to populations without status [13]. Recommendations are made for practice include: education and training for healthcare providers on access to care and health and human rights [15, $16,28,31,32]$; improving access to services [17, 19]; and including documentation of immigration status in medical records [29].

\section{Discussion}

Our review of the literature illustrates how the health of people without status in Canada is shaped by structural and intermediary determinants. Applying a postcolonial perspective to the WHO SDoH framework, we examine the $\mathrm{SDoH}$ not as passively existing entities, but as factors produced by a global neocolonial and neoliberal regime, operating both in Canada and internationally to create stark social and health inequity [7]. It is our position, supported by the literature, that the structural determinants of health shape the opportunities available to people without status in Canada and how they are viewed by the Canadian public and service providers in particular $[16,18,25,36]$. People without status are held responsible for their lack of status, are not offered pathways for regularization, and are kept in precarious positions of deportability [17, 34]. The symbolic and material consequences of the structural determinants of health are evident in our analysis of the intermediary determinants, a confluence of factors that result in poor living and working conditions and limited access to healthcare and social services $[15,18,24,26,35,42,43]$. These intermediary determinants are direct effects of the precarity institutionalized by structural determinants $[4,14,16,17,24,30]$, and they lead to the health consequences described above.

In this review, we have challenged traditional biomedical interpretations of health by including studies that explore experiences of stress, weakness, and fatigue, among other broad health consequences. While not specific medical diagnoses, these issues constitute an undeniable burden on the health of people without status in Canada. Still, while there is a clearly documented negative impact of being without 


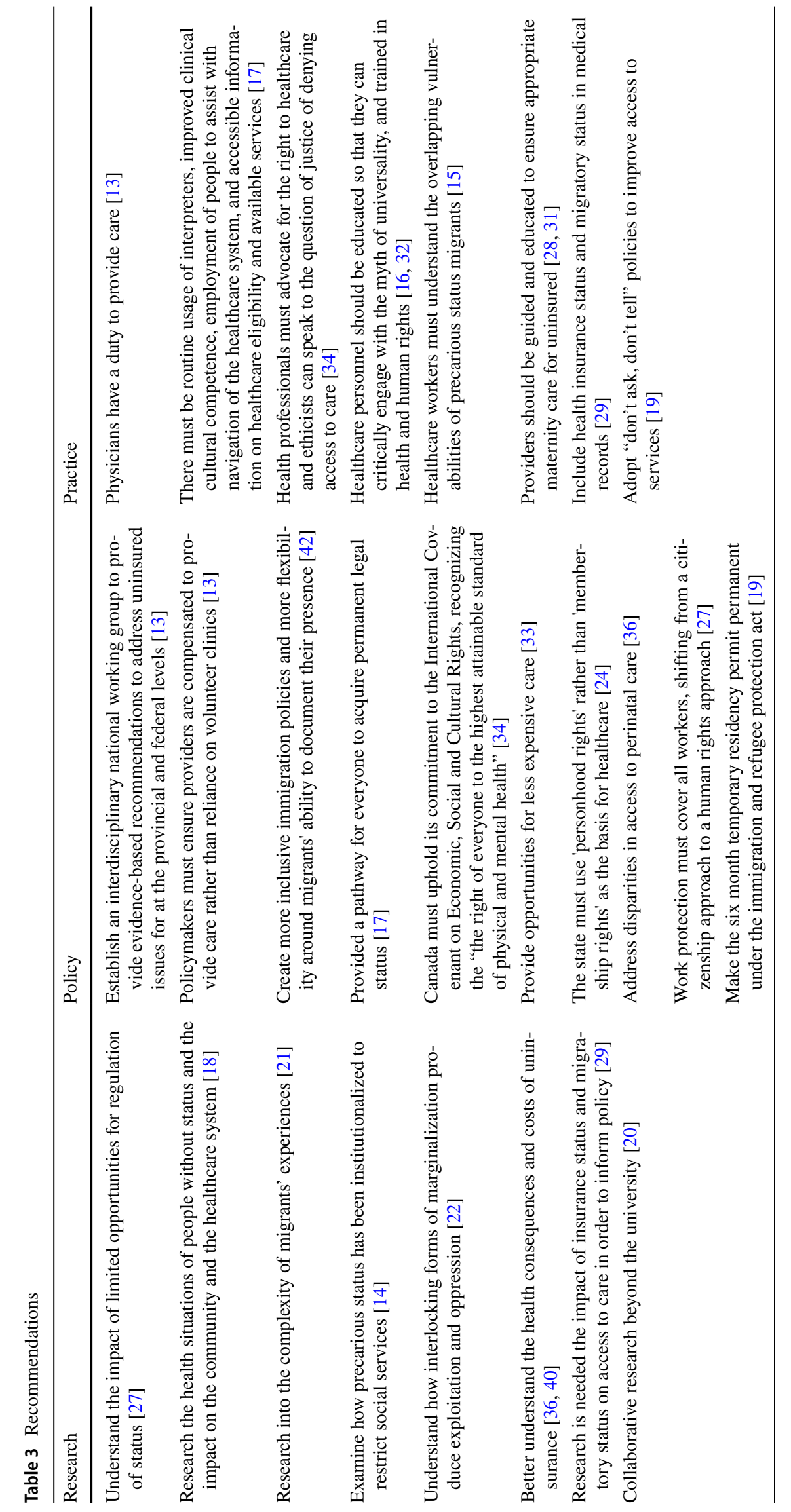


status in Canada on overall health and wellbeing, we found a dearth of research on specific health consequences for this population. We hypothesize that this is due in part to the difficulty inherent in studying a population that is not identifiable through standard demographic methods, as well as to the limited conceptualization of health currently used by clinicians and researchers in the health sciences. The lack of data is a sign of the invisibilization of people without status in Canada.

Our analysis reveals that immigration status is the foundational determinant of health for people without status in Canada. The intersection of the structural determinants of health with socially entrenched occupational prestige, patriarchy, heteronormativity, racialization, and xenophobia, among others, can lead to multiple social positions. For instance, being a white, heterosexual European immigrant with permanent status produces a starkly different social position than being a Black, transgender Latina immigrant without status. Non-status immigrants tend to occupy a very low social position in Canadian society. In Fig. 1 we synthesize the structural determinants (socioeconomic and political contexts), social positions, and intermediary determinants affecting the health of people without status in Canada to show how health inequity is produced. The elements found in this literature review are represented (e.g. temporariness and invisibilization), along with other features of Canadian society (e.g. racism and shadism) that contribute to inequity, particularly in terms of health consequences. Depending on how the SDoH are manifested in everyday life, health consequences may vary considerably. Therefore, Fig. 1 does not represent a singular experience for all people without status in Canada. The synthesis is a visual representation of potential intersections that could lead to differential forms of health inequity. Our goal is to offer a reminder to policymakers, service providers, and researchers that while people without status live in the same society, their unique political, social and economic circumstances, which are produced both internationally and in Canada, determine their health differently from those with secure immigration status.

\section{Future Directions}

It is our view that understanding the unique social position of people without status, produced by structural and

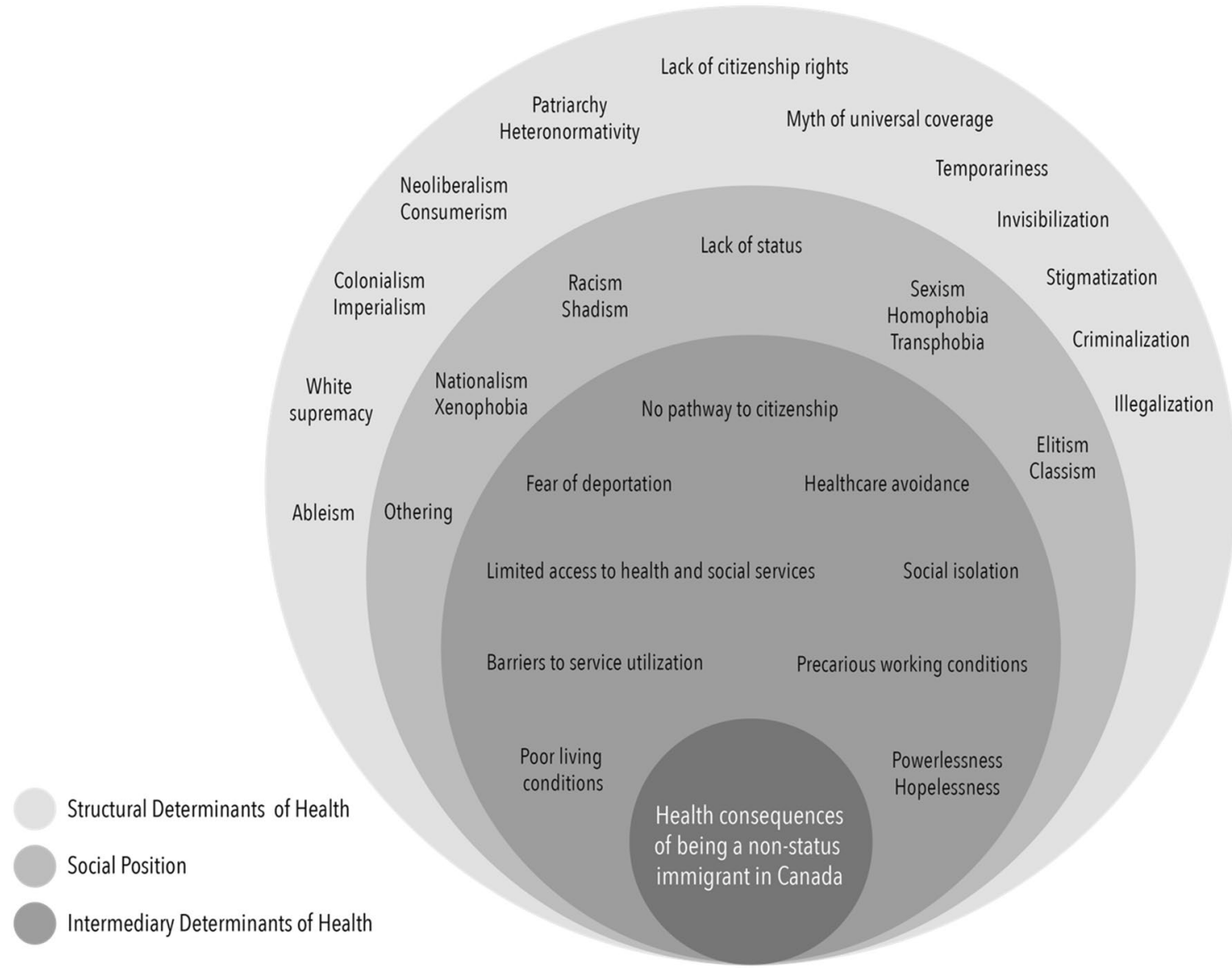

Fig. 1 The production of health inequity for non-status immigrants in Canada 
intermediary determinants of health, can help improve social and health services and policies that shape these services, thereby improving health outcomes for people without status in Canada. As our review demonstrates, service providers in Canada tend to work from uninformed and/or prejudicial positions vis-à-vis people without status, perpetuating stigmatizing discourses and enacting exclusionary practices $[4$, $14,16,18,26]$. While some provinces offer limited means of accessing care for people without status, the existence of separate pathways for care perpetuates differential care based on immigration status, contributing to a tiered, rather than universal, healthcare system. A more comprehensive and sustainable solution that does not discriminate based on immigration status is needed.

More well-funded and interdisciplinary research could help to fill some of the persisting knowledge gaps highlighted by our review. Together, social and health scientists and community partners can produce research towards a fuller understanding of the broad health and social consequences of the marginalization and exploitation of people without status in Canada. This visibilization of the impact of lack of status on health could lead to policy changes to decrease inequity. However, it is important to note that visibility may also cause political backlash against existing programs and services for people without status, potentially limiting currently available opportunities to access services. Given that maintaining the confidentiality of people without status is vital to avoid the risk of deportation, research requires time, diligence, and the prioritization of individual and family safety.

\section{Limitations}

The major limitation of this study is the exclusion of nonpeer reviewed literature, including books, theses, and gray literature. Given the challenges involved in studying the non-status immigrant population in Canada, there may be important insights in gray literature.

\section{Conclusions}

Our findings are in agreement with Magalhães et al.'s [5] assertion that "having no-status is a significant form of social exclusion which renders immigrants vulnerable to structural conditions" (p. 148). The SDoH impact everyone's life in Canada, but being without status results in particular forms of deprivation and exploitation that negatively impact health and wellbeing. Problematically, the WHO SDoH framework does not highlight immigration status as a determinant of health, even though lack of status affects millions of people around the globe. The inattention to lack of immigration status is a clear gap in the framework. The grave health impact of being without status can no longer be denied. Our findings demonstrate that the intersection of other determinants of health with lack of immigration status has compounding effects that lead to diminished health and quality of life.

At the time of writing, we in Canada and around the world are facing the unprecedented threat of COVID-19. During the pandemic, strong activism on access to healthcare in Canada has prompted provincial governments to acknowledge the injustice of immigration status-based prohibitions on access to healthcare. For example, the Ontario government passed a policy to grant all people access to medically necessary health services regardless of immigration and insurance status during the pandemic [45]. Unfortunately, the government maintains that this is a temporary change, set to return to previous restrictions when the pandemic ends. It is our hope that this paper will contribute to a growing body of evidence demonstrating the negative health consequences of restricting access to healthcare on the basis of immigration status, and that access to healthcare and other social services will be expanded into the future.

Acknowledgements Stephanie Sanger, Clinical Services Librarian at McMaster University Department of Health Sciences, helped to create the search protocol for this study.

Funding Monica Gagnon's doctoral studies are supported in part by funding from the Social Sciences and Humanities Research Council of Canada.

\section{Declarations}

Conflict of interest The authors have no relevant financial or non-financial interests to disclose.

Human or Animal Participants Ethics board review was not required, as this article is a scoping review and the research did not involve human or animal participants.

\section{References}

1. International Organization for Migration. Key Migration Terms. https://www.iom.int/key-migration-terms\#Irregular-migration. Accessed 1 Jul 2021.

2. Gastaldo D, Carrasco C, Magalhães L: Entangled in a web of exploitation and solidarity: Latin American undocumented workers in the Greater Toronto Area. 2012. http://www.migrationh ealth.ca/undocumented-workers-ontario/summary-findings. Accessed 1 Jul 2021.

3. Goldring L, Landolt P: The conditionality of legal status and rights: conceptualizing precarious non-citizenship in Canada: In: Goldring L, Landolt P, eds. Producing and negotiating noncitizenship: precarious legal status in Canada. Toronto: University of Toronto Press; 2013;3-27.

4. Goldring L, Berinstein C, Bernhard JK. Institutionalizing precarious migratory status in Canada. Citizsh Stud. 2009;13(3):239-65. 
5. Magalhães L, Carrasco C, Gastaldo D. Undocumented migrants in Canada: a scope literature review on health, access to services, and working conditions. J Immigr Minor Health. 2010;12(1):132-51.

6. Castañeda H, Holmes SM, Madrigal DS, Young MED, Beyeler N, Quesada J. Immigration as a social determinant of health. Annu Rev Public Health. 2015;36:375-92.

7. Walia H. Undoing border imperialism. Washington, DC: AK Press; 2013.

8. Mbembe A. Necropolitics. Durham: Duke University Press; 2019.

9. Santos BS. The end of the cognitive empire. Durham: Duke University Press; 2018.

10. Solar O, Irwin A. A conceptual framework for action on the social determinants of health: social determinants of health discussion paper 2. Policy and Practice: World Health Organization; 2010.

11. Marmot M. The health gap- the challenge of an unequal world. London: Bloomsbury Press; 2015.

12. Arksey H, O'Malley L. Scoping studies: towards a methodological framework. Int J Soc Res Methodol. 2005;8(1):19-32.

13. Caulford P, D'Andrade J. Health care for Canada's medically uninsured immigrants and refugees: whose problem is it? Can Fam Phys. 2012;58(7):725-7.

14. Vanthuyne K, Meloni F, Ruiz-Casares M, Rousseau C, RicardGuay A. Health workers' perceptions of access to care for children and pregnant women with precarious immigration status: health as a right or a privilege? Soc Sci Med. 2013;93:78-85.

15. Hanley J, Gravel S, Lippel K, Koo J-H. Pathways to healthcare for migrant workers: How can health entitlement influence occupational health trajectories? Pistes - Perspectives Interdisciplinaires sur le Travail et la Sante. 2014;16(2):1-21.

16. Ruiz-Casares M, Rousseau C, Derluyn I, Watters C, Crepeau F. Right and access to healthcare for undocumented children: addressing the gap between international conventions and disparate implementations in North America and Europe. Soc Sci Med. 2010;70(2):329-36.

17. Chen YYB. The future of precarious status migrants' right to health care in Canada. Alberta Law Rev. 2017;54(3):649-64.

18. Brabant $\mathrm{Z}$, Raynault MF. Health of migrants with precarious status: results of an exploratory study in Montreal-Part B. Soc Work Public Health. 2012;27(5):469-81.

19. Pashang S. Entrapped bodies: illegalized trafficked youth in Canada. Int J Ment Heal Addict. 2019;17:370-84.

20. Meloni F, Rousseau C, Ricard-Guay A, Hanley J. Invisible students: institutional invisibility and access to education for undocumented children. Int J Migrat Health Soc Care. 2017;13(1):15-25.

21. Ellis BD, Stam HJ. Cycles of deportability: threats, fears, and the agency of 'irregular' migrants in Canada. Migr Stud. 2018;6(3):321-44.

22. Villegas PE. Fishing for precarious status migrants: surveillant assemblages of migrant illegalization in Toronto. Canada J Law Soc. 2015;42(2):230-52.

23. Villegas FJ. "Don't ask, don't tell": examining the illegalization of undocumented students in Toronto, Canada. Br J Sociol Educ. 2018;39(8):1111-25.

24. Da Lomba S. Immigration status and basic social human rights: a comparative study of irregular migrants' right to health care in France, the UK, and Canada. Netherlands Q Human Rights. 2010;28(1):6-40.

25. Bhuyan R. Negotiating citizenship on the frontlines: how the devolution of Canadian immigration policy shapes service delivery to women fleeing abuse. Law Policy. 2012;34(2):211-36.

26. Bhuyan R, Osborne BJ, Cruz JFJ. Once you arrive, se ta sala todo (everything is salted): Latina migrants' search for "dignity and a right to life" in Canada. J Immigr Refug Stud. 2016;14(4):411-31.

27. Goldring L, Landolt P. Caught in the work-citizenship matrix: the lasting effects of precarious legal status on work for Toronto immigrants. Globalizations. 2011;8(3):325-41.

28. Munro K, Jarvis C, Kong LY, D’Souza V, Graves L. Perspectives of family physicians on the care of uninsured pregnant women. J Obstet Gynecol Canada. 2013;35(7):599-605.

29. Rousseau C, Laurin-Lamothe A, Rummens JA, Meloni F, Steinmetz N, Alvarez F. Uninsured immigrant and refugee children presenting to Canadian paediatric emergency departments: disparities in help-seeking and service delivery. Paediatr Child Health. 2013;18(9):465-9.

30. Hari A, Liew JCY. Introduction to special section on: precarity, illegality and temporariness: implications and consequences of Canadian migration management. Int Migr. 2018;56(6):169-75.

31. Mattatall FM. uninsured maternity patients in Calgary: local trends and survey of health care workers. J Obstet Gynecol Canada. 2017;39(11):1015-20.

32. Ruiz-Casares M, Rousseau C, Laurin-Lamothe A, Rummens J, Zelkowitz P, Crepeau F, Steinmetz N. Access to health care for undocumented migrant children and pregnant women: the paradox between values and attitudes of health care professionals. Matern Child Health J. 2013;17(2):292-8.

33. Bennett N, Burton N. Midwives responding to the needs of uninsured clients: old order and new immigrant women in midwifery care. Can J Midwifery Res Pract. 2012;11(3):8-17.

34. Marks JH. The undocumented unwell. Hastings Cent Rep. 2013;43(1):10-1.

35. Miklavcic A. Canada's non-status immigrants: negotiating access to health care and citizenship. Med Anthropol. 2011;30(5):496-517.

36. Wilson-Mitchell K, Rummens JA. Perinatal outcomes of uninsured immigrant, refugee, and migrant mothers and newborns living in Toronto, Canada. Int J Environ Res Public Health. 2013;10(6):2198-213.

37. Campbell RM, Klei AG, Hodges BD, Fisman D, Kitto S. A comparison of health access between permanent residents, undocumented immigrants and refugee claimants in Toronto, Canada. J Immigr Minor Health. 2014;16(1):165-76.

38. Hynie M, Ardern C, Robertson A. Emergency room visits by uninsured child and adult residents in Ontario, Canada: what diagnoses, severity, and visit disposition reveal about the impact of being uninsured. J Immigr Minor Health. 2016;18(5):948-56.

39. Chen YYB, Li AT, Fung KP, Wong JP. Improving access to mental health services for racialized immigrants, refugees, and non-status people living with HIV/AIDS. J Health Care Poor Underserved. 2015;26(2):505-18.

40. Jarvis C, Munoz M, Graves L, Stephenson R, D'Souza V, Jimenez V. Retrospective review of prenatal care and perinatal outcomes in a group of uninsured pregnant women. J Obstet Gynecol Canada. 2022;33(3):235-43.

41. Tenenbaum S, Singer K. Borders of belonging: challenges in access to anti-oppressive mental health care for Indigenous Latinx gender-fluid border-youth. Alter Native Int J Indig Peoples. 2018;14(3):245-50.

42. Villegas PE. "I can't even buy a bed because I don't know if I'll have to leave tomorrow": temporal orientations among Mexican precarious status migrants in Toronto. Citizsh Stud. 2014;18(3-4):277-91.

43. Tungohan E. Living with compromised legal status: irregular temporary foreign workers in Alberta and the importance of imagining, strategizing, and inter-provincial legal consciousness. Int Migr. 2018;56(6):207-20. 
44. Bunn S, Fleming P, Rzeznikiewiz D, Leung F-H. Understanding the demographic characteristics and health of medically uninsured patients. Can Fam Physician. 2013;59(6):e276-81.

45. Ontario Ministry of Health: COVID-19 expanding access to OHIP coverage and funding physican and hospital services for uninsured patients. Ontario: Government of Ontario 2020 Mar 25; Bulletin no.: 4749. http://www.health.gov.on.ca/en/pro/ programs/ohip/bulletins/4000/bul4749.aspx. Accessed 1 Nov 2020 .
Publisher's Note Springer Nature remains neutral with regard to jurisdictional claims in published maps and institutional affiliations. 